7. Reprod. Fert. (1967) 13, 237-249

\title{
THE BUOYANT DENSITY OF BOVINE AND RABBIT SPERMATOZOA
}

\author{
R. G. BENEDICT*, V. N. SGHUMAKER $\dagger$ AND R. E. DAVIES \\ Department of Animal Biology and the Graduate Group on Molecular Biology, \\ School of Veterinary Medicine, University of Pennsylvania, Philadelphia, \\ Pennsylvania, U.S.A.
}

(Received 7th March 1966)

Summary. Zonal isopycnic gradient centrifugation has been employed as a method for the separation of intact spermatozoa on the basis of the differing buoyant densities of the cells. Spermatozoa from rabbits and cattle were studied, and materials used for the gradient solutions have included sodium chloride, sodium nitrate, potassium tartrate, potassium iodide, caesium chloride, glycerol, sucrose, Ficoll, bovine serum albumin, a colloidal silica solution and the methyl glucamine salt (MGU) of 3,5di-iodo-4-pyridone- $\mathrm{N}$-acetic acid (umbradilic acid). Linear density gradients were pre-formed with a gradient machine, and the diluted washed cells were layered as a lamella on the gradient. A normal population of spermatozoa was separated by the zonal isopycnic centrifugation into two density classes: a low-density class and a high-density class. The relative amounts of cells in each class varied with the type and maturity of cells, the pretreatment and the conditions of the centrifugation. The low-density class of cells had a buoyant density of 1.16 to $1.19 \mathrm{~g} / \mathrm{ml}$ in all solutions employed; the high-density class has buoyant density values depending upon the solute employed for the gradient solutions and varying from 1.25 to $1.32 \mathrm{~g} / \mathrm{ml}$. The separation of the cells into two classes appears to be on the basis of the permeability of the cells, as ageing, physical treatment or chemical treatment lead to an increased amount of cells in the high-density class. The cells in the high-density fraction show no apparent differences in their size or structure, but show a lower motility and fertility and a greater eosinophilia than the cells in the low-density fractions. The high-density class divides further into two sub-classes over a narrow range of densities. This subdivision may be on the basis of the differing dry weight compositions of the cells which is made evident by the replacement of internal water with external solvent.

\section{INTRODUCTION}

The mean specific gravity of bull spermatozoa was reported by Lindahl \& Kihlstrom (1952) as in the range $1 \cdot 240$ to $1 \cdot 334$. Such values were obtained by

* Present address: Eastern Utilization Research and Development Division, U.S. Dept. Agriculture, Wyndmoor, Penna.

$\dagger$ Present address: Molecular Biology Institute, University of California, Los Angeles, California. 
suspension of the cells in aqueous solutions of the methyl glucamine salt of 3,5-di-iodo-4-pyridone- $\mathrm{N}$-acetic acid (MGU) of differing concentrations and densities and noting the percentage which sedimented after centrifugation at $2300 \mathrm{~g}$ for $10 \mathrm{~min}$. Unripe spermatozoa, as characterized by the presence of cytoplasmic droplets, were observed to have a significantly lower specific gravity than the ripe and over-ripe cells. The ripening process was implied as involving a continuous rise in density.

Isopycnic gradient centrifugation offers a more effective method of determining the densities of particles. Attempts to employ non-gradient sedimentation of cells has resulted in convective disturbances and anomalous results. Non-isopycnic gradients have been employed for the separation by gravity sedimentation of spermatozoa (Bhattacharya, 1962) whereby the separation is on the basis of the size or shape of the cell rather than the differences in the densities. Such separations, however, are subject to gross error from any aggregation of the cells which would result in a more rapid sedimentation. The effectiveness of such a separation and the time required for separation increases as the density of the supporting medium is brought closer to the density of the particle. In the method of isopycnic gradient centrifugation, the particles are centrifuged in a gradient which encompasses the range of densities that the particle may possess. The particle will migrate in the centrifugal field until the effective forces acting upon the particle vanish. At this position, the buoyant density of the particle is equivalent to the density of the solution at that location and travel essentially ceases. The sedimentation of particles may be expressed by the equation:

$$
\frac{d x}{d t}=\frac{2 r_{0}^{2}}{9 \eta} \frac{\left(\rho_{\rho}-\rho_{s}\right) \boldsymbol{g}}{\left(f \mid f_{0}\right)}
$$

where the velocity of the particle, $d x / d t$, is proportional to the radius of the equivalent sphere $r_{0}$, the density difference $\left(\rho_{0}-\rho\right.$ solution $)$, the centrifugal field strength, $\boldsymbol{g}$, and inversely proportional to the solution viscosity, $\eta$, and a shape factor $f \mid f_{0}$. Such a procedure has been employed extensively for the determination of the density of viruses (McCrea, Epstein \& Barry, 1961); subcellular particles (de Duve, Berthet \& Beaufay, 1959); proteins (Cox \& Schumaker, 1961); and nucleic acids (Meselson, Stahl \& Vinograd, 1957). An effective medium for isopycnic gradient centrifugation should be physiologically inert, and should not produce changes in the volume, mass or density of the particle. In addition, such a medium should be also of low viscosity and osmotic pressure and capable of forming solutions of high densities. No one substance satisfies all of these requirements, but sucrose and caesium chloride have been employed in most density gradient centrifugations, the former for cell particulates, the latter for nucleic acids, proteins and viruses.

Density gradient centrifugation of intact cells has been limited to those cells which are normally discrete, blood cells and spermatozoa. Erythrocytes have been separated in an isotonic albumin solution (Lief \& Vinograd, 1964), and leucocytes have been separated from erythrocytes by centrifugation through a polysucrose solution of constant density (Biggers \& McFeely, 1963).

Gradient centrifugation using discontinuous gradients has been employed 
for the separation of sperm heads and tails by Masaki \& Hartree (1962) and for the separation of spermatozoa from epididymal debris for chemical analyses (Dawson \& Scott, 1964). This technique has also been investigated as a possible means of separating spermatozoa on the basis of their nucleic acid content for the predetermination of sex. This procedure was suggested by Harvey (1946) who calculated values of $1.07132 \mathrm{~g} / \mathrm{ml}$ for the male-determining spermatozoa and $1.0715 \mathrm{~g} / \mathrm{ml}$ for the female-determining spermatozoa, based on the apparent density of $1.0715 \mathrm{~g} / \mathrm{ml}$ for human spermatozoa in a $20 \%$ dextrin medium. Previously, Lush (1925) had experimented using differential centrifugation of rabbit spermatozoa without employing gradients, and found no significant separation of sexes in the litters from the inseminated spermatozoa. Lovelock (1960) noted a separation into two density classes, approximately 1.18 and $1.25 \mathrm{~g} / \mathrm{ml}$, by centrifugation of rabbit spermatozoa through a gradient of albumin solutions, but noted no difference in the sex ratios of the litters from the high-density and the low-density sperm cells. The values for the densities of the albumin solutions employed, however, are apparently in error, as the maximum density possible from a saturated albumin solution is $1.12 \mathrm{~g} / \mathrm{ml}$, and the $30 \%$ albumin solution employed for the dense solution has a density of approximately $1.08 \mathrm{~g} / \mathrm{ml}$. Beatty (1964) employed dialysed colloidal silica solutions and dextran solutions for his centrifugations and noted that approximately $95 \%$ of the spermatozoa were in the specific gravity range 1.09 to 1.18 $\mathrm{g} / \mathrm{ml}$, and that the mean specific gravity was $1 \cdot 132 \mathrm{~g} / \mathrm{ml}$.

Because of the wide diversity of the values reported in the literature for the density of spermatozoa, it was of interest to determine a possible basis for these discrepancies.

\section{MATERIALS AND METHODS}

Rabbit semen was collected from healthy adult bucks with an artificial vagina, and was diluted with a non-calcium Ringer's solution (Mann, 1946). Bull semen was purchased undiluted.

Substances examined which could form aqueous solutions with densities between 1.15 and $1.40 \mathrm{~g} / \mathrm{ml}$ were the following: sodium chloride, sodium nitrate, potassium tartrate, potassium iodide, caesium chloride, glycerol and sucrose. In addition, 'Ficoll', a polysucrose substance produced by Pharmacia, Uppsala, Sweden; 'Ludox', a colloidal silica solution produced by E. I. du Pont de Nemours Company, Wilmington, Delaware, U.S.A.; bovine serum albumin; and the methyl glucamine salt of 3,5-di-iodo-4-pyridone- $\mathrm{N}$-acetic acid (umbradilic acid) were also examined as media. The crystalline bovine serum albumin was dissolved in glass distilled water and was dialysed successively against an $0.01 \mathrm{~m}$-ethylenediamine tetra-acetic acid, di-sodium salt solution (EDTA), deionized water, the modified non-calcium Ringer's solution containing 0.001 M-2-mercaptoethanol, and finally against deionized water, following which it was freeze-dried. The methyl glucamine and the umbradilic acid portions of the salt were each recrystallized three times from ethanol and water, respectively, before formation of the salt. Solutions of known composition were prepared from each of the above substances, and the refractive indices and the densities 
(measured pycnometrically) were determined. The mean specific volume was determined from the slope on a graphical plot of the density reciprocal against the weight per cent composition. The values for maximum density, mean specific volume and refractive index increment are shown in Table 1 . The refractive index of the solution was used as the indicator of solution density in various fractions, requiring only $0.02 \mathrm{ml}$ for a determination.

The gradients were preformed with a gradient machine (Benedict, 1964) based on a modification of that of Bock \& Ling (1954). This machine was constructed entirely of plastics to minimize metallic contamination. The gradients, usually $5.0 \mathrm{ml}$ in volume, were layered into cellulose centrifuge tubes (Beckman Industries, No. 305050) and layered with $0.10 \mathrm{ml}$ of the diluted semen sample as a lamella. The tubes were centrifuged in a Beckman ultracentrifuge, Model L, for various times and speeds, using a Beckman SW39 swinging bucket rotor.

TABle 1

CHARACTERISTICS OF SOLUTIONS EMPLOYED FOR DENSITY GRADIENTS

\begin{tabular}{l|c|c|c}
\hline \multicolumn{1}{c|}{ Solution } & $\begin{array}{c}\text { Maximum density } \\
(\mathrm{g} / \mathrm{ml})\end{array}$ & $\begin{array}{c}\text { Partial specific } \\
\text { volume }(\mathrm{ml} / \mathrm{g})\end{array}$ & $\begin{array}{c}\text { Change refractive index/ } \\
\text { Change density }\end{array}$ \\
\hline Sodium chloride & 1.196 & 0.375 & 0.2453 \\
Ludox & 1.219 & - & 0.1174 \\
Ficoll & 1.230 & 0.691 & 0.4773 \\
Glycerol & 1.260 & 0.794 & 0.5144 \\
Sodium nitrate & 1.368 & 0.457 & $0 \cdot 1364$ \\
Sucrose & 1.473 & 0.639 & 0.3841 \\
Potassium tartrate & 1.485 & 0.407 & 0.2133 \\
MGU Solution & 1.614 & 0.484 & 0.3111 \\
Potassium iodide & 1.633 & 0.404 & $0 \cdot 1762$ \\
Caesium chloride & 1.918 & 0.264 & 0.0971 \\
\hline
\end{tabular}

MGU is the abbreviation for the methyl glucamine salt of umbradilic acid (3,5-di-iodo4-pyridone-N-acetic acid).

The density for the Ludox solution is that of the commercially furnished stabilized product.

The centrifuged tubes were photographed by illuminating the tube from beneath by a microscope stage lamp while the tube was held by forceps in a vertical position. The tubes werefractionated by puncturing the bottom of the tube with a No. 25 gauge hypodermic needle connected to a polyethylene catheter, and mounted in a rubber stopper in the glass tube holding the centrifuge tube. The flow rate of the solution could be controlled and drops collected by means of a clamp on the catheter. The drops were examined for refractive index and for direct microscopic examination. The light scattering effect at $400 \mathrm{~m} \mu$ of the cells was also employed as a method for quantitating the cell concentration of the different fractions after dilution.

Only a very rough approximation of the density of spermatozoa can be made from the values for mass and volume found in the literature. The dry mass $\left(\times 10^{-12} \mathrm{~g}\right)$ of whole bull spermatozoa has been listed as ranging from 16.5 (Bhargava, Bishop \& Work, 1959) to between 24 and 29 (Redenz, 1933). If one assumes a hydration of $50 \%$ (Barer, 1956), the mass of the intact sperm cell 
would range from between 33 to $58 \times 10^{-12} \mathrm{~g}$. Similarly, the measurements of cell volume show a similar variation. Calculation of the volume from the listed dimensions (Saacke, 1962) gives a value of 22.5 $\mu^{3}$. Bishop \& Walton (1960) reveal that no reliable estimates of the volume of the sperm cell have been made but that a consideration of the dimensions suggests a volume of $30 \mu^{3}$. Employing this value for the volume, the densities calculated from the extreme wet weights range between 1.10 and $1.90 \mathrm{~g} / \mathrm{ml}$. With Iversen's data (1964) of the average volume of the bull sperm head as 11 to $13 \mu^{3}$ and the volume of the tail as 3 to $4 \mu^{3}$, these densities would range between 1.94 and $4 \cdot 14 \mathrm{~g} / \mathrm{ml}$.

By calculation of the probable mean specific gravity of the bull sperm head from the literature values for composition, Kihlstrom (1958) reported a value of 1.29 to 1.30 . The values which he employed for his calculations were: DNA (specific gravity of 2.00 ) $-45 \%$ dry weight; protein (specific gravity of $1 \cdot 35$ ) $-55 \%$ dry weight; lipid-disregarded; water (specific gravity of $1 \cdot 0$ ) $-52 \%$ of total weight. These values give a percentage composition for the sperm head of $21.6 \%$ DNA, $26.4 \%$ protein and $52 \%$ water. For the whole sperm cell the following values represent the most likely composition in percentage dry weight: lipid (specific gravity of 0.9 ) $-11 \%$; DNA (specific gravity of 2.0 ) $-21 \%$; protein (specific gravity of 1.35 ) $-68 \%$ by difference. A hydration value of $50 \%$ is again assumed. The formula for the calculation of density from the per cent composition is:

$$
\rho=\frac{\text { Mass }}{\text { Volume }}=\frac{M_{1}+M_{2}+M_{3} \ldots M_{n}}{V_{1}+V_{2}+V_{3} \ldots V_{n}}=\frac{\Sigma M_{n}}{\Sigma V_{n}}=\frac{\Sigma M_{n}}{\Sigma \frac{M_{n}}{\rho_{n}}}
$$

where $M_{n}$ and $\rho_{n}$ are the mass and densities of the individual components. The apparent density for the sperm head, using the above formula, is $1.214 \mathrm{~g} / \mathrm{ml}$, and a value for $1.15 \mathrm{~g} / \mathrm{ml}$ for the whole sperm cell.

\section{RESULTS AND DISCUSSION}

The results of using the above substances for the formation of density gradients in the centrifugation of bull spermatozoa is shown in Pl. 1, Fig. 1. With the exception of these experiments in which Ficoll, glycerol and potassium iodide were used, two bands of differing density were observed in these tubes: a lowdensity band near $1.17 \mathrm{~g} / \mathrm{ml}$, and a high-density band at various density values. In the Ficoll-containing solution, the high viscosity of the solution prevented band separation during the conditions of the experiment. With potassium iodide, on the other hand, the high-density band actually pelleted on the bottom of the tube at a density greater than $1.38 \mathrm{~g} / \mathrm{ml}$. With glycerol, the maximum density $(100 \%$ glycerol $)$ appears to be less than the density of the spermatozoa; there was no low-density band evident in the glycerol density gradient. Sodium chloride, bovine serum albumin and Ludox solutions are not shown. With sodium chloride, the spermatozoa pelleted on the tube bottom at a density greater than the maximum density of the salt solution $(1.19 \mathrm{~g} / \mathrm{ml})$. The high viscosities and low maximum densities of the albumin solutions produced pelleting of the spermatozoa only if the tubes were centrifuged for long periods 
at high speeds. The Ludox solutions scattered light such that the photographs did not show the location of the spermatozoa.

The employment of the solution which had been used by Lindahl \& Kihlstrom (1952) for their determinations (MGU) for the gradient after centrifugation of bull spermatozoa for $5 \mathrm{~min}$ at $15,000 \mathrm{rev} / \mathrm{min}$ in the SW39 swinging bucket rotor gave a tube distribution which is shown in PI. 1, Fig. 2. The densitometer tracings of the photographic negative and the density values as determined by refractometry are shown. The formation of these two sub-bands from the high-density band during centrifugation in MGU was unexpected.

Since a requirement of a medium for density gradients was that it be physiologically inert, the various media above were tested for their effect on the spermatozoa. Using motility of the cells after dilution back into the modified Ringer's solution as the criterion, the non-lethal media were: bovine serum albumin, Ficoll, Ludox and MGU solution. Because conditions for centrifugation in albumin and Ficoll solutions are not ideal, due to the high viscosities of the concentrated solutions, and because of gelation and lowered motility produced in the Ludox solutions, it was decided to employ MGU solutions for the other experiments. To determine the effects of time, temperature and speed of centrifugation on the banding characteristics of bull spermatozoa in the MGU solutions, time of centrifugation studies were performed at $5^{\circ}, 25^{\circ}$ and $37^{\circ} \mathrm{C}$ at rotor speeds of $5000,15,000$ and $30,000 \mathrm{rev} / \mathrm{min}$ in the SW39 rotor. The same sample of bull semen was employed for all runs. The tubes were first centrifuged for $5 \mathrm{~min}$ at a particular speed and temperature in each experiment. The centrifuge was then stopped, the tube removed, photographed and then returned for additional centrifugation. Photographs were taken after 5,15 and $30 \mathrm{~min}$ of centrifugation. The photographic results are shown in Pl. 2, Fig. 1. The middle portion of the bands were sampled with a polyethylene catheter attached to a hypodermic syringe, and the refractive indices of these samples taken. The values of the refractive indices, the corresponding density value and the age of the semen when the run was performed are shown in Table 2.

In all instances, the densities of the upper band were $1 \cdot 170 \pm 0.025 \mathrm{~g} / \mathrm{ml}$, and the densities of the lower bands were $1.290 \pm 0.040 \mathrm{~g} / \mathrm{ml}$. Some of the variation is produced by the sampling technique. From an examination of the results, it was observed that an increase in the temperature and the time of exposure in the medium caused an increase in the material found in the lower bands. Aggregation of the cells and the use of a wide gradient (in most instances from

\section{EXPLANATION OF PLATE 1}

FIG. 1. Density gradient centrifugation of bull spermatozoa in different gradients. The tubes show the main equilibrium banding positions of bull spermatozoa following zonal isopycnic centrifugation through wide-range density gradients of the above eight aqueous solutions.

Frg. 2. Equilibrium density distribution of bull spermatozoa in a MGU gradient. The densitometer tracing was made from the photographic negative. MGU refers to aqueous solutions of the methyl glucamine salt of umbradilic acid. The tubes were illuminated from below by a microscope stage lamp. The apparent bands at the meniscus and tube bottom are produced from light reflection and are not from sperm concentration. The tube length is $51 \mathrm{~mm}$. The density values listed reflect the apparent density $(\mathrm{g} / \mathrm{ml})$ of the bull spermatozoa in the main bands (arrows), as well as the tube top and bottom. 
PLATE 1

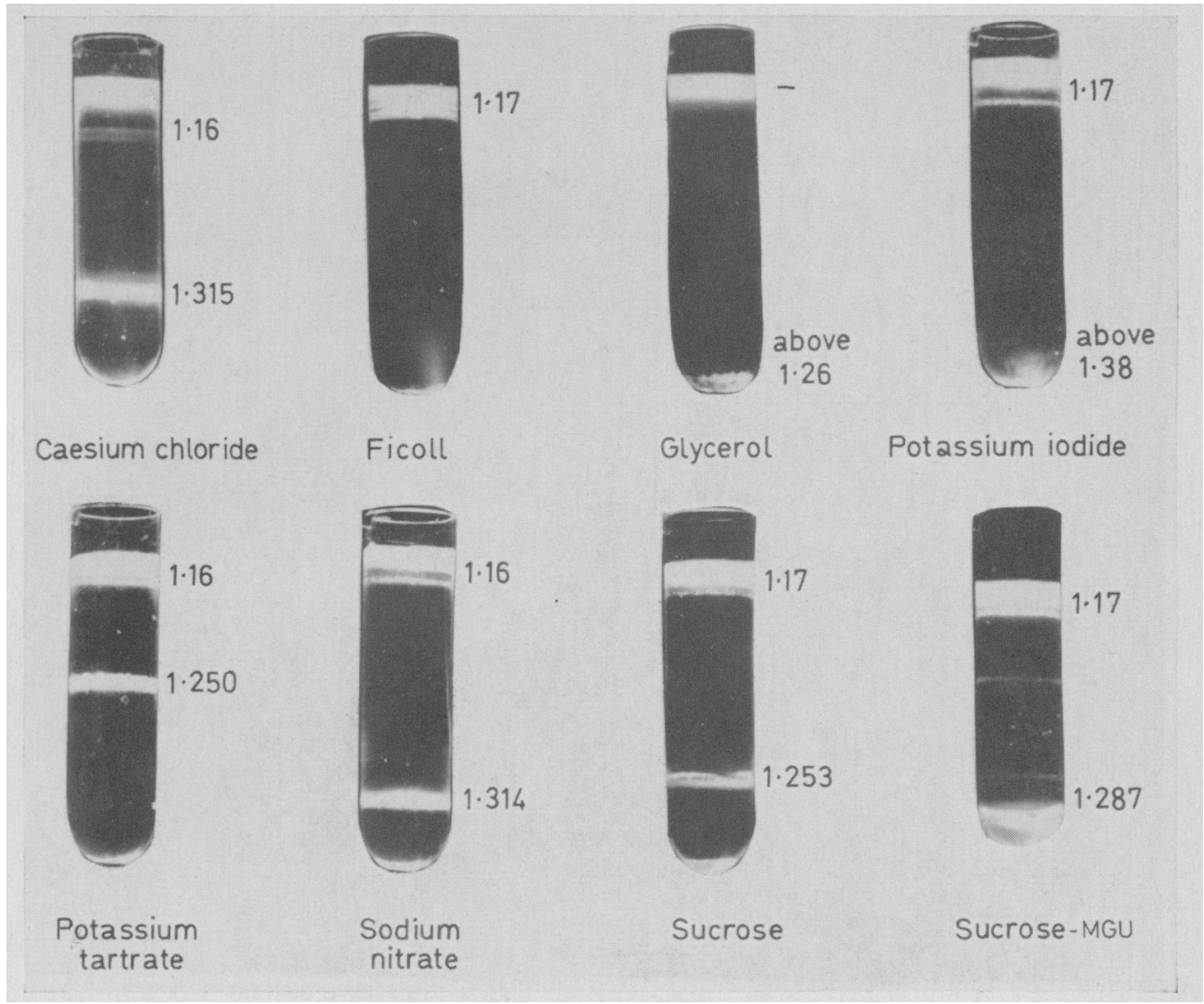

Fig. 1

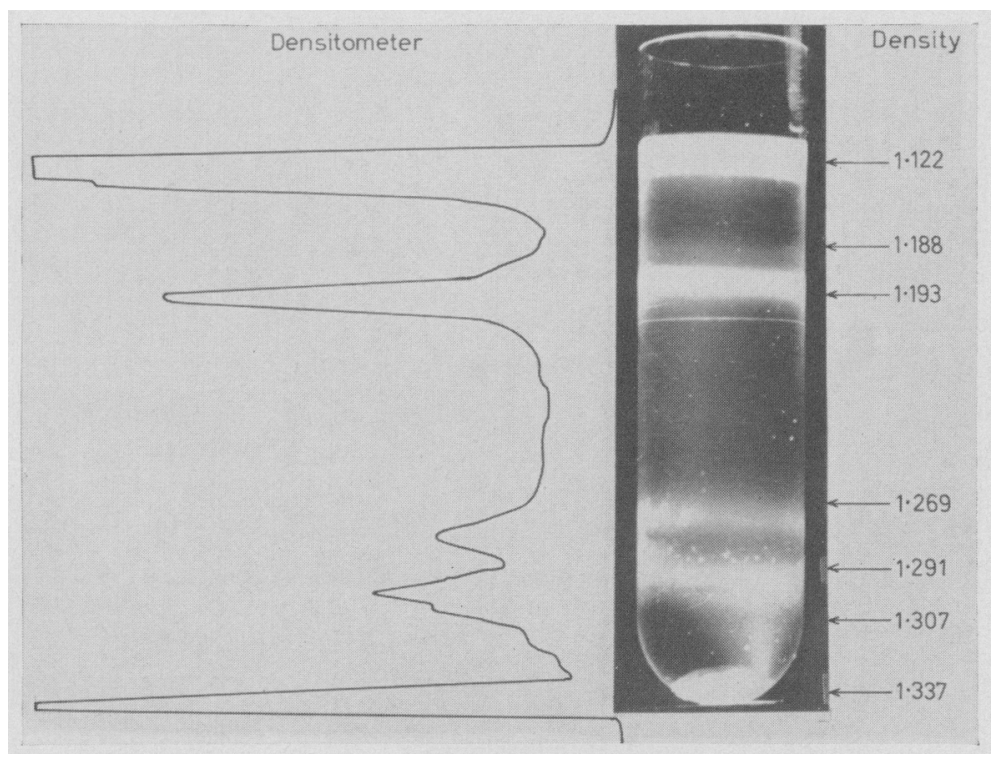

FIG. 2 
PLATE 2

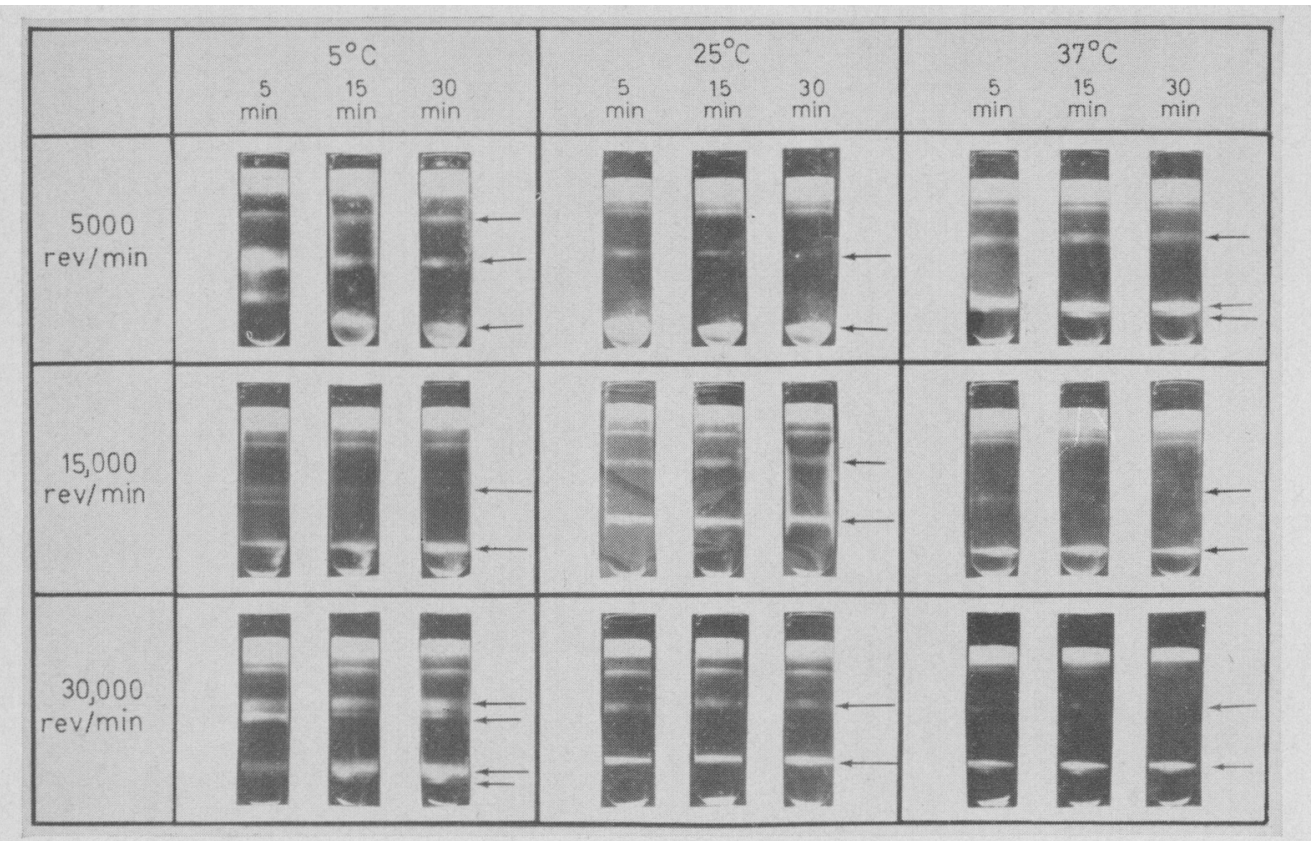

Fig. 1. Effect of time of centrifugation, speed of centrifugation and temperature of centrifugation on bull spermatozoa in a MGU gradient. The arrows refer to the principal bands of spermatozoa and correspond to the density values listed in Table 3 . The thin band at the top of the tube under the meniscus reflection has a density of approximately $1 \cdot 10 \mathrm{~g} / \mathrm{ml}$, and was produced by cellular debris present in the semen sample.

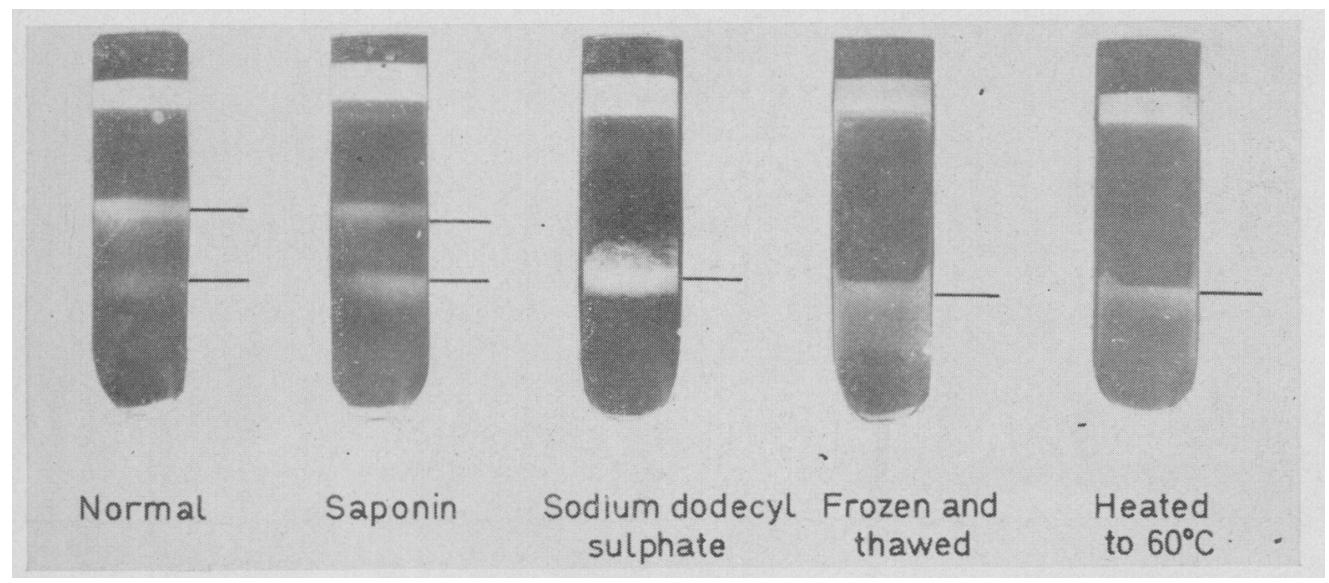

FIG. 2. Behaviour of spermatozoa in MGU gradients after various treatments. The treatments included exposure to a $0.001 \%$ solution of saponin or a $1 \%$ solution of sodium dodecyl sulphate for $30 \mathrm{~min}$, freezing and thawing of the cells 3 times within $10 \mathrm{~min}$, or heating at $60^{\circ} \mathrm{C}$ for $1 \mathrm{~min}$. All of the above treatments caused the concentration of cells to decrease in the low-density band and to increase in the high-density band. All gradients in Figs. 1 and 2 (Plate 2) are wide-range, from a density of approximately $1.08 \mathrm{~g} / \mathrm{ml}$ at the top to approximately $1.33 \mathrm{~g} / \mathrm{ml}$ at the bottom, with some variation between tubes.

(Facing p. 243) 
1.05 to $1.35 \mathrm{~g} / \mathrm{ml}$ ) obscured the resolution of the bottom band into its two components, as noted in Pl.1, Fig. 2.

To determine if these bands were produced by the conditions of the experiments, the tubes were sampled in other experiments and the bands were recentrifuged on fresh gradients. The upper band, upon recentrifugation, gave rise to an upper band and the lower bands. The lower bands produced only a diffuse band at their original density value. The conversion of a portion of the upper band to the lower bands appears to be occurring with time in our experiments. Two high-density bands and little or no low density bands were also noted in experiments where the semen samples were mixed with the concentrated MGU solution and layered on the bottom of the tube before the gradient

TABLE 2

VARIATION OF DENSITY DISTRIBUTION WITH TIME, TEMPERATURE AND SPEED OF CENTRIFUGATION

\begin{tabular}{|c|c|c|c|c|c|c|c|c|c|}
\hline \multirow{3}{*}{$\underset{(\text { rev/min })}{\text { Speed }}$} & \multicolumn{9}{|c|}{ Temperature of experiment } \\
\hline & \multicolumn{3}{|c|}{$5^{\circ} \mathrm{C}$} & \multicolumn{3}{|c|}{$25^{\circ} \mathrm{C}$} & \multicolumn{3}{|c|}{$37^{\circ} \mathrm{C}$} \\
\hline & $\begin{array}{c}\text { Age } \\
(\text { days })\end{array}$ & R.I. & Density & $\begin{array}{c}\text { Age } \\
\text { (days) }\end{array}$ & R.I. & Density & $\underset{(\text { days })}{A g e}$ & R.I. & Density \\
\hline 5000 & 7 & $\begin{array}{c}* \\
1 \cdot 3870 \\
1.4190\end{array}$ & $\begin{array}{c}* \\
1 \cdot 177 \\
1 \cdot 279\end{array}$ & 7 & $\begin{array}{l}1.3850 \\
1.4210\end{array}$ & $\begin{array}{l}1 \cdot 170 \\
1 \cdot 282\end{array}$ & 5 & $\begin{array}{l}1.3825 \\
1.4180 \\
1.4345\end{array}$ & $\begin{array}{l}1 \cdot 160 \\
1 \cdot 278 \\
1.230\end{array}$ \\
\hline 15,000 & 7 & $\begin{array}{l}1.3850 \\
1.4200\end{array}$ & $\begin{array}{l}1 \cdot 170 \\
1 \cdot 280\end{array}$ & 4 & $\begin{array}{l}1.3820 \\
1.4195\end{array}$ & $\begin{array}{l}1 \cdot 160 \\
1 \cdot 280\end{array}$ & 7 & $\begin{array}{l}1.3820 \\
1.4195\end{array}$ & $\begin{array}{l}1 \cdot 160 \\
1 \cdot 280\end{array}$ \\
\hline 30,000 & 5 & $\begin{array}{l}1 \cdot 3835 \\
\mathrm{I} \cdot 3900 \\
1 \cdot 4180 \\
1 \cdot 4300\end{array}$ & $\begin{array}{l}1 \cdot 161 \\
1 \cdot 183 \\
1 \cdot 278 \\
1 \cdot 317\end{array}$ & 4 & $\begin{array}{l}1.3850 \\
1.4245\end{array}$ & $\begin{array}{l}1 \cdot 170 \\
1.298\end{array}$ & 5 & $\begin{array}{l}1.3850 \\
1.4245\end{array}$ & $\begin{array}{l}1 \cdot 170 \\
1 \cdot 298\end{array}$ \\
\hline
\end{tabular}

Density is value in $\mathrm{g} / \mathrm{ml}$ at $25^{\circ} \mathrm{C}$.

Age refers to the age of the sperm cells when centrifuged. R.I. is the refractive index measured at $25^{\circ}$ C. Density values (at $25^{\circ} \mathrm{C}$ ) were converted from the refractive index values.

* This band is also observed in the other photographs in Pl. 2, Fig. 1. This band at the top of the tube has a density of approximately $1 \cdot 10 \mathrm{~g} / \mathrm{ml}$ and is caused by cell debris in the semen samples.

was added, or where the semen sample was mixed with the low-density MGU solution and layered on top of the gradient. The two high-density sub-bands were also noted in overnight equilibrium runs and in centrifuge runs in which the spermatozoa were mixed with one or both of the solutions employed for the manufacture of the gradients before centrifugation. The two upper bands produced at $30,000 \mathrm{rev} / \mathrm{min}$ at a temperature of $5^{\circ} \mathrm{C}$ have not been noted in other centrifuge runs. Other attempts to split the low-density upper band into sub-bands, similar to the behaviour of the high-density bands, have been unsuccessful.

In other experiments where the tubes were fractionated after centrifugation, the refractive indices and optical densities of the various fractions were determined and plotted. A representative graph is shown in Text-fig. 1. From these graphs the refractive index and the corresponding density for the fraction with the maximum concentration of sperm cells could be determined. The density 
values for rabbit and bull spermatozoa are shown in Table 3, from various fractionation experiments. Rabbit semen samples also contain prostatic particles in addition to the spermatozoa which sedimented at a lower rate and formed a diffuse zone during sedimentation in the range of $1.24 \mathrm{~g} / \mathrm{ml}$. These values were omitted from the table.

Since it was possible that the spermatozoa might be separating in the gradient centrifugation on the basis of shape or size rather than on the basis of density,

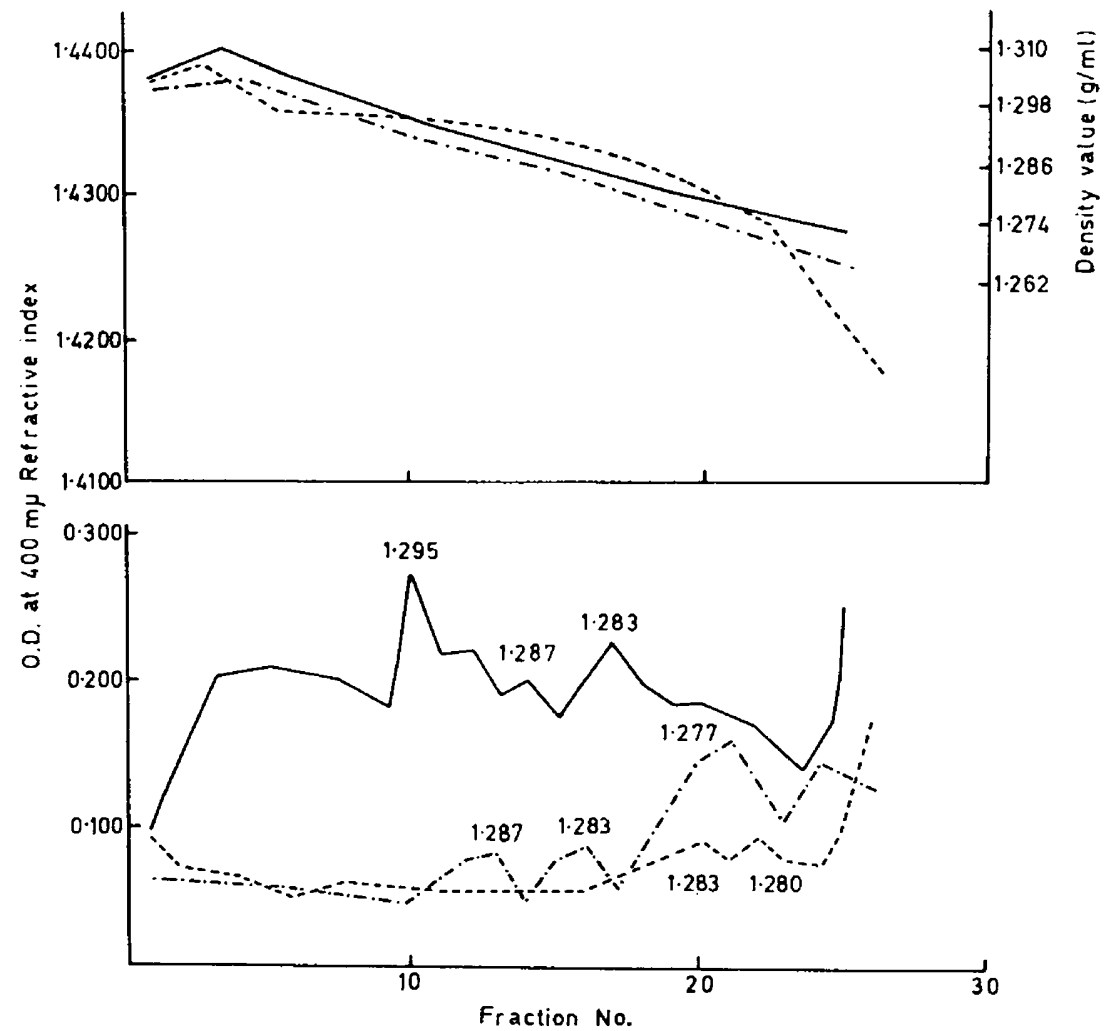

TEXT-FIG. 1. Fractionation graphs of human $(-\cdots \cdot)$, rabbit $(-\cdot-\cdot-)$ and bull $(-)$ spermatozoa centrifuged in a narrow range, high-density MGU gradient. The upper graph shows the refractive indices of the fractions of the gradients. The density values on the right are in $\mathrm{g} / \mathrm{ml}$ and correspond to the refractive index values for the same ordinate location. The lower graph indicates the optical density measured at $400 \mathrm{~m} \mu$ of the fraction diluted with water to $1.0 \mathrm{ml}$ total volume, and is a turbidometric measure of the sperm concentration.

it was important to show that the size or shape was not changed by the centrifugation through the gradient. Many cells, such as red blood cells, and most sub-cellular particles behave as osmometers and swell or shrink in relation to the osmotic pressure of the solution in which they are located. Their size may be expected to vary in a gradient centrifugation where the concentration and the osmotic pressure of the solution used to form the gradient are frequently varied greatly. The size and shape of the spermatozoa from different layers in an MGU gradient and from untreated semen were examined under a magnification of 1500 , using phase contrast microscopy and an ocular micrometer. The 
dimensions of the sperm cells from the different fractions are shown in Table 4. There was no significant change in the shape of the cells, nor in the size of the cells, from the centrifugations through the gradients as observed under the light microscope.

TABLE 3

DENSITY VALUES OF BULL AND RABBIT SPERMATOZOA

\begin{tabular}{|c|c|c|c|c|c|c|c|}
\hline \multirow{2}{*}{\multicolumn{2}{|c|}{$\begin{array}{l}\text { Sperm } \\
\text { sample }\end{array}$}} & \multicolumn{2}{|c|}{ Low-density fraction } & \multicolumn{4}{|c|}{ High-density fractions } \\
\hline & & Range & Mean & Range & Mean & Range & Mean \\
\hline \multirow[t]{11}{*}{ Bull } & \multirow{11}{*}{$\begin{array}{r}1 \\
2 \\
3 \\
4 \\
5 \\
6 \\
7 \\
8 \\
9 \\
10 \\
11 \\
12 \\
13 \\
14 \\
15 \\
16\end{array}$} & $1 \cdot 150-1 \cdot 206$ & $1 \cdot 182$ & $1.260-1.318$ & $1 \cdot 287$ & & \\
\hline & & $1 \cdot 180-1 \cdot 210$ & $1 \cdot 200$ & $\begin{array}{l}1 \cdot 268-1 \cdot 296 \\
1 \cdot 268-1 \cdot 283\end{array}$ & $\begin{array}{l}1.285 \\
1.275\end{array}$ & $\begin{array}{l}1.303-1.324 \\
1.286-1.300\end{array}$ & $\begin{array}{l}1.315 \\
1.292\end{array}$ \\
\hline & & $1 \cdot 160-1 \cdot 190$ & $1 \cdot 170$ & $1.272-1.292$ & $1 \cdot 284$ & $1 \cdot 300-1 \cdot 314$ & 1.306 \\
\hline & & $1 \cdot 183-1 \cdot 197$ & $1 \cdot 188$ & $1 \cdot 276-1 \cdot 290$ & $1 \cdot 283$ & $1 \cdot 300-1 \cdot 314$ & $1 \cdot 309$ \\
\hline & & $1.155-1.218$ & 1.190 & $1 \cdot 255-1.283$ & $1 \cdot 270$ & $1 \cdot 287-1 \cdot 310$ & $1 \cdot 298$ \\
\hline & & $1 \cdot 153-1 \cdot 226$ & $1 \cdot 188$ & $1 \cdot 276-1 \cdot 316$ & $1-298^{*}$ & & \\
\hline & & $1 \cdot 185-1 \cdot 201$ & $1 \cdot 192$ & & & $1 \cdot 310-1 \cdot 320$ & $1 \cdot 315$ \\
\hline & & & & $1.281-1 \cdot 290$ & $1 \cdot 287 *$ & 1000 & \\
\hline & & $1 \cdot 188-1 \cdot 193$ & $1 \cdot 187$ & $\begin{array}{l}1.280-1.200 \\
1.280-1.298 \\
1.283\end{array}$ & $\begin{array}{l}1.203 \\
1.291 \\
1.279\end{array}$ & $\begin{array}{l}1.300-1.305 \\
1.290-1.306\end{array}$ & $\begin{array}{l}1.293 \\
1.302 \\
1.299\end{array}$ \\
\hline & & & & $1.287-1.290$ & 1.289 & $1.293-1.298$ & 1.295 \\
\hline & & $1 \cdot 160-1 \cdot 207$ & $1 \cdot 183$ & $1 \cdot 276-1 \cdot 300$ & $1 \cdot 290$ & $1 \cdot 300-1 \cdot 320$ & 1.306 \\
\hline \multicolumn{2}{|c|}{ Average } & $(1 \cdot 150-1 \cdot 226)$ & $\begin{array}{c}1 \cdot 187 \\
\pm 0.0077\end{array}$ & $(1 \cdot 255-1 \cdot 318)$ & $\begin{array}{c}1.283 \\
\pm 0.0062\end{array}$ & $(1 \cdot 286-1 \cdot 324)$ & $\begin{array}{c}1.303 \\
\pm 0.0076\end{array}$ \\
\hline Rabbi & $\begin{array}{l}1 \\
2 \\
3 \\
4\end{array}$ & $\begin{array}{l}1 \cdot 150-1 \cdot 208 \\
1 \cdot 150-1 \cdot 210\end{array}$ & $\begin{array}{l}1 \cdot 182 \\
1 \cdot 188\end{array}$ & $\begin{array}{l}1 \cdot 278-1 \cdot 306 \\
1 \cdot 278-1 \cdot 302 \\
1 \cdot 274-1 \cdot 280 \\
1 \cdot 273-1 \cdot 280\end{array}$ & $\begin{array}{l}1 \cdot 302 * \\
1.295 \\
1.277 \\
1 \cdot 277\end{array}$ & $\begin{array}{l}1 \cdot 308-1 \cdot 313 \\
1 \cdot 286-1 \cdot 290 \\
1 \cdot 280-1 \cdot 290\end{array}$ & $\begin{array}{l}1.311 \\
1 \cdot 287 \\
1.283\end{array}$ \\
\hline \multicolumn{2}{|c|}{ Average } & $(1 \cdot 150-1 \cdot 210)$ & $1 \cdot 185$ & $(1 \cdot 273-1 \cdot 306)$ & $1 \cdot 283$ & $(1 \cdot 280-1 \cdot 313)$ & 1.294 \\
\hline
\end{tabular}

* Indicates a skewed peak indicative of incomplete separation of peaks not included in calculation of averages.

TABLE 4

DIMENSIONS OF BULL SPERMATOZOA UNDER LIGHT MICROSCOPY

\begin{tabular}{l|r|r|r|r}
\hline \multicolumn{1}{c|}{ Sample } & Head length & Head width & Neck length & Total length \\
\hline Uncentrifuged & $10 \cdot 3 \pm 0 \cdot 73$ & $5 \cdot 0 \pm 0 \cdot 39$ & $12 \cdot 1 \pm 1 \cdot 27$ & $71 \cdot 0 \pm 4 \cdot 0$ \\
Top fraction & $10 \cdot 0 \pm 0 \cdot 69$ & $5 \cdot 4 \pm 0 \cdot 44$ & $13 \cdot 2 \pm 0 \cdot 60$ & $70 \cdot 0 \pm 1 \cdot 3$ \\
Middle fraction & $9 \cdot 9 \pm 0 \cdot 59$ & $5 \cdot 4 \pm 0 \cdot 55$ & $13 \cdot 4 \pm 0 \cdot 85$ & $68 \cdot 5 \pm 3 \cdot 0$ \\
Bottom a fraction & $9 \cdot 8 \pm 0.44$ & $5 \cdot 4 \pm 0.38$ & $13.3 \pm 0.94$ & $73 \cdot 0 \pm 2 \cdot 0$ \\
Bottom b fraction & $9 \cdot 7 \pm 0 \cdot 18$ & $5 \cdot 6 \pm 0.35$ & $13 \cdot 2 \pm 0 \cdot 61$ & $71 \cdot 3 \pm 1 \cdot 1$ \\
\hline
\end{tabular}

Dimensions are given in microns. The fractions are those separated in a mGu gradient by a zonal centrifuge run. The values are arithmetical means of ten individual determinations. The standard deviation of the mean $\left[\frac{\Sigma(\bar{x}-x)^{2}}{(n-1)}\right]^{1 / 2}$ is shown for the determinations.

An alternate explanation for the high-density bands produced under the differing conditions is that permeation of the cell occurs in the concentrated salt solutions with the resultant substitution of external solvent for some or all of the internal water within the cell. Experiments were conducted to test the hypothesis that the banding behaviour was produced by differences in the 
permeability of the cells. These involved the behaviour in gradients of sperm samples exposed to different treatments, the differential staining behaviour with eosin of the different bands, and fertility experiments with artificial insemination with the separated fractions.

Such treatments as heating and freeze-thawing in the absence of glycerol have been shown by Saacke (1962) to cause damage to the cell membranes of the spermatozoa. Surface-active agents cause changes in the cell surface and loss of intracellular constituents (White \& McLeod, 1963). The results obtained in the density gradient centrifugation of bull spermatozoa which had been exposed to a $0.001 \%$ solution of saponin, a $1 \%$ solution of sodium dodecyl sulphate, heated for $\mathrm{I}$ min at $60^{\circ} \mathrm{C}$, or frozen and thawed three times within $10 \mathrm{~min}$, are shown in Pl. 2, Fig. 2, where they are compared with an untreated sample.

\section{TABLE 5}

EOSIN STAINING CHARACTERISTICS OF DIFFERENT FRACTIONS

\begin{tabular}{|c|c|c|c|c|c|c|c|}
\hline & \multirow[t]{2}{*}{ Sample } & \multicolumn{2}{|c|}{$\begin{array}{l}\text { (Low-density) } \\
\text { Top fraction }\end{array}$} & \multicolumn{2}{|c|}{$\begin{array}{l}\text { (High-density) } \\
\text { Bottom fraction }\end{array}$} & \multicolumn{2}{|c|}{ Uncentrifuged } \\
\hline & & No. & $\%$ & No. & $\%$ & No. & $\%$ \\
\hline Fresh & $\begin{array}{l}\text { Eosin }(+) \\
\text { Eosin }(-)\end{array}$ & $\begin{array}{r}43 \\
168\end{array}$ & $\begin{array}{l}20 \cdot 4 \\
79 \cdot 6\end{array}$ & $\begin{array}{l}78 \\
86\end{array}$ & $\begin{array}{l}47 \cdot 6 \\
52 \cdot 4\end{array}$ & $\begin{array}{l}108 \\
600\end{array}$ & $\begin{array}{l}15 \cdot 2 \\
84.8\end{array}$ \\
\hline Aged & $\begin{array}{l}\text { Eosin }(+) \\
\text { Eosin }(-)\end{array}$ & $\begin{array}{l}68 \\
46\end{array}$ & $\begin{array}{l}59 \cdot 6 \\
40 \cdot 4\end{array}$ & $\begin{array}{r}203 \\
16\end{array}$ & $\begin{array}{r}92 \cdot 7 \\
7 \cdot 3\end{array}$ & $\begin{array}{r}316 \\
30\end{array}$ & $\begin{array}{r}91 \cdot 3 \\
8 \cdot 7\end{array}$ \\
\hline Mixed* & $\begin{array}{l}\text { Eosin }(+) \\
\text { Eosin }(-)\end{array}$ & $\begin{array}{r}76 \\
212\end{array}$ & $\begin{array}{l}26 \cdot 4 \\
73 \cdot 7\end{array}$ & $\begin{array}{r}100 \\
41\end{array}$ & $\begin{array}{l}70 \cdot 9 \\
29 \cdot 1\end{array}$ & $\begin{array}{l}383 \\
357\end{array}$ & $\begin{array}{l}51 \cdot 8 \\
48 \cdot 2\end{array}$ \\
\hline
\end{tabular}

* Fresh and aged.

In all cases, the treatments caused a decrease in the quantity of spermatozoa present in the lower-density band and an increase in the number of spermatozoa in the higher-density band. The low concentration of saponin employed presumably caused only a portion of the cells to be affected.

Lasley, Easley \& McKenzie (1942) have reported that the rejection of eosin dye by certain species of spermatozoa is an indication of the viability of the spermatozoa. The eosinophilic sperm cells are presumed to be dead; in a mixed population of cells, the non-motile cells will be stained with eosin whereas the motile cells will be unstained. The basis of this differential staining is not known, but does not appear to be from an irreversible binding of the dye with the cell. In initial attempts to use the eosinophilic properties of the spermatozoa, a population of spermatozoa were stained with an eosin solution and then centrifuged through a MGU density gradient. Upon fractionation of the sample, it was observed that none of the sperm cells within the gradient were stained with eosin. The permeation of the eosinophilic spermatozoa appears to be reversible. Upon the passage of the cells through the gradient, the eosin within the permeable cells leached out into the gradient solution by simple diffusion. Since this method could not be used, the alternate method of staining cells after removal from the gradient was employed. Three solutions of bull spermatozoa, one fresh, one 7 days old and one a mixture of the fresh and aged 
samples, were centrifuged through the gradients composed of MGU solutions. The upper and lower bands were collected from each, were washed and suspended in Ringer's solution and were stained with the differential staining solution. Fifteen random fields were examined from each band. The numbers of eosin-positive and eosin-negative spermatozoa and the percentages of each are shown in Table 5. While both kinds of spermatozoa are present in both bands, the eosin positive cells are in all cases present in a higher percentage in the high-density bands.

Rabbits were employed for the experiments in which the different bands in the gradients were used for artificial inseminations. Ovulation was induced by the administration of $50 \mathrm{i} . \mathrm{u}$. of HCG following the insemination with a specially designed glass insemination pipette (Maule, 1962). All samples employed for insemination contained a minimum of 100,000 cells. The data from the artificial insemination experiments are shown in Table 6.

TABLE 6

SUMMARY OF THE ARTIFICIAL INSEMINATION OF RABBITS EMPLOYING BANDS OF SPERMATOZOA FROM DENSITY GRADIENT GENTRIFUGATION

\begin{tabular}{l|c|c|c|c|c}
\hline \multicolumn{1}{c|}{ Fraction in tube } & $\begin{array}{c}\text { No. of does } \\
\text { inseminated }\end{array}$ & $\begin{array}{c}\text { No. } \\
\text { died }\end{array}$ & $\begin{array}{c}\text { No. } \\
\text { pregnant }\end{array}$ & $\begin{array}{c}\text { Percentage } \\
\text { 'fertility' }\end{array}$ & $\begin{array}{c}\text { Sex of } \\
\text { litters }\end{array}$ \\
\cline { 1 - 2 } $\begin{array}{l}\text { Uncentrifuged } \\
\text { (control) }\end{array}$ & 15 & 3 & 7 & 58 & $20 \mathrm{M}, 14 \mathrm{~F}, 5 \mathrm{U}$ \\
$\begin{array}{l}\text { Top band } \\
\text { (low density) }\end{array}$ & 12 & 1 & 4 & 36 & $4 \mathrm{M}, 1 \mathrm{~F}, 6 \mathrm{U}$ \\
$\begin{array}{l}\text { Middle of tube } \\
\text { Combined bottom } \\
\text { bands (ab) } \\
\text { (high density) }\end{array}$ & 10 & 1 & 1 & 11 & $5 \mathrm{M}, 1 \mathrm{~F}$ \\
$\begin{array}{l}\text { Bottom upper band (a) } \\
\text { Bottom lower band (b) }\end{array}$ & 16 & 0 & 1 & 6 & $5 \mathrm{M}, 3 \mathrm{~F}$ \\
$\quad$ Totals & 124 & 0 & 1 & 4 & $1 \mathrm{M}, 1 \mathrm{~F}$ \\
\hline
\end{tabular}

Percentage 'fertility' refers to percentage of does littering of those inseminated and viable. The sex was determined both by gross anatomical examination of the foetal gonads and by histological examination.

$M$ refers to male gonads; $F$ refers to female gonads; and $U$ refers to unidentified where the gonads were unidentified because of cannibalism or improper fixation of the foetus.

The above data suggests strongly that the true density of the intact bull sperm cell or the rabbit sperm cell is between 1.16 and $1.19 \mathrm{~g} / \mathrm{ml}$, as evidenced by the values determined from the upper band in the different gradients employed. The values near 1.28 to $1.29 \mathrm{~g} / \mathrm{ml}$ found in the MGU solutions by Lindahl \& Kihlstrom (1952) and by us for bull spermatozoa are produced by such conditions as extended exposure to the medium, warm temperature and the ageing of the cells. The centrifugation did not appear to change the size and shape of the spermatozoa, as examined under light microscopy. Saacke (1962), however, reported that the bull spermatozoa exposed to hypertonic solutions of sodium citrate appeared morphologically normal when examined with the light microscope, but showed cell damage in the midpiece area (ruptured cell membranes and mitochondrial cristae) when examined under the electron microscope. Other experiments with treatments of the spermatozoa 
with detergents or freeze-thawing and the results with eosin staining and fertility indicate that the behaviour of the spermatozoa in the density gradients appears to be the result of the separation of the cells on the basis of permeability differences. It is difficult, however, to separate the effect of increased permeability from that of cell death. Eosin staining of spermatozoa also appears to be a permeability effect rather than a viability effect. Death may precede the permeability increase and such cells would not stain readily if permeability is a prerequisite for dye uptake. If permeability preceded death of the cell (and an increased permeability may be presumed to lead to cellular death if continued for an extended period), the eosin would stain cells which are not actually dead. Such a sequence of events may help to explain the anomalous results obtained with eosin staining reported by Salisbury \& VanDemark (1961). Our results with artificial insemination of the separated bands also indicate that the high-density bands still retain some fertility, indicating that the separation is not entirely a separation on the basis of viability, but rather one on the basis of permeability.

The separation of the high density band into two sub-bands (Pl. 1, Fig. 2) appears to be caused as a result of the permeability of the cell and the differentiation of the population further by an apparent change in composition. The effect is particularly evident in the gradients from MGU solutions, but has been observed in gradients composed of other materials also where coagulation does not occur. The low-density band which is not permeable generally shows but one wide band. This band width may be caused by a heterogeneity in cell densities. If non-permeable cells contain different amounts of water (the constituent most likely to vary with metabolism, age or stage of maturation), the densities of these cells would vary, obscuring any density differences caused by the differing amounts of DNA or protein. Upon penetration of the spermatozoa by the gradient-forming medium, this variable amount of liquid no longer contributes to the buoyant density; and the density differences due to variations in the content of DNA or protein are thereby resolved. The formation of two sub-bands in the high density fraction indicates that the relative composition of the solids in the cell is also varied. If the solid constituents remained in the same relationship, while the water percentage was varied, the replacement of water by the solution would be expected to produce a single high-density band similar to the low-density band rather than the two sub-bands.

Other experiments (Benedict \& Davies, unpublished results) indicate that the buoyant density of the spermatozoa increases during its passage through the epididymis, but that any particular buoyant density may include several types of spermatozoa (unripe, ripe, overripe) resulting from differences in composition and the overlapping of the classes. The presence of these overlapping classes may explain the wide band of densities in the lower-density region.

\section{ACKNOWLEDGMENTS}

A portion of this investigation was aided by a pre-doctoral fellowship, GM-15, 356 from the National Institutes of Health to one of us (RCB). The authors are indebted to the Atlantic Breeders Cooperative, Lancaster, Pennsylvania, for 
supplying the bull semen samples, and to Dr Arthur Dannenberg, Dr John D. Biggers and Dr Rufus Creed for their assistance with certain aspects of the artificial insemination of rabbits.

\section{REFERENCES}

BARer, R. (1956) Phase contrast and interference microscopy in cytology. Physical Techniques in Biological Research, Vol. 3, p. 63. Eds. G. Oster and A. W. Pollister. Academic Press, New York.

BeatTy, R. A. (1964) Density gradient media for mammalian spermatozoa. $V^{\circ}$ Congresso internazionale per la Riproduzione animale e la Fecondzione artificiale, Trento. p. 276.

BENEDICT, R. C. (1964) Density gradient centrifugation of mammalian spermatozoa. Ph.D. thesis, University of Pennsylvania.

Bhargava, P. M., Bishop, M. W. H. \& Work, T. S. (1959) The chemical composition of bull semen with special reference to nucleic acids, free nucleotides, and free amino acids. Biochem. 7. 73, 242.

Bhattacharya, A. B. C. (1962) Sedimentationgeswindigheit der X- und Y-Spermien. Z. wiss. Zool. $166,203$.

Biggers, J. D. \& McFeeley, R. A. (1963) A simple method for the display of chromosomes from cultures of white blood cells with special reference to the ox. Nature, Lond. 199, 718.

Bishop, M. W. H. \& Walton, A. (1960) Spermatogenesis and the structure of mammalian spermatozoa. Marshall's Physiology of Reproduction, chap. 7. Ed. A. S. Parkes. Longmans, Green, London.

Bock, R. M. \& Ling, N. (1954) Devices for gradient elution in chromatography. Analyt. Chem. 26, 1543.

Cox, D. J. \& Schumaker, V. N. (1961) The preferential hydration of proteins in concentrated salt solutions. II. Sedimentation equilibrium of proteins in salt density gradients. F. Am. chem. Soc. 83, 2439.

Dawson, R. M. C. \& Scotr, T. W. (1964) Phospholipid composition of epididymal spermatozoa prepared by density gradient centrifugation. Nature, Lond. 202, 292.

de Duve, C., Berthet, J. \& Beaufay, H. (1959) Gradient centrifugation of cell particles: Theory and applications. Prog. Biophys. biophys. Chem. 9, 325.

Harvey, N. E. (1946) Can the sex of mammalian offspring be controlled ? F. Hered. 37, 71.

IVERSEN, S. (1964) Surface reflexion interference microscopy of bull spermatozoa. Q. $\mathcal{F l ~ m i c r . ~ S c i . ~ 1 0 5 , ~}$ 245.

Kinzstrom, J. E. (1958) Specific gravity of different parts of bull spermatozoa. Ark. Zool. 2, 11, 35.

Lasley, J. F., Easley, G. I. \& McKenzie, F. F. (1942) A staining method for the differentiation of live and dead spermatozoa. I. Applicability to the staining of ram spermatozoa. Anat. Rec. 82, 167.

Lief, R. C. \& VinogRAD, J. (1964) The distribution of buoyant density of human erythrocytes in bovine albumin solutions. Proc. nain. Acad. Sci. U.S.A. 51, 520.

Lindahl, P. E. \& Kinlstrom, J. E. (1952) Alterations in specific gravity during the ripening of bull spermatozoa. F. Dairy Sci. 35, 393.

Lovelock, J. E. (1960) Comment on the possibility of controlling sex ratio and development. In: Sex Differentiation and Development. Mem. Soc. Endocr. 7, 113.

Lush, J. L. (1925) The possibility of sex control by artificial insemination with centrifuged spermatozoa. 7. agric. Res. 30, 893.

MANN, T. (1946) Studies on the metabolism of semen. III. Fructose as a normal constituent of seminal plasma. Biochem. F. 40, 481.

MASAKI, I. \& HARTREE, E. F. (1962) Distribution of metabolic activity, phospholipid, and hyaluronidase between the heads and tails of bull spermatozoa. Biochem. F. 84, 347 .

MAULE, J. P. (1962) The semen of animals and artificial insemination, p. 323. Commonwealth Agricultural Bureaux, Farnham Royal, England.

MCCReA, J. F., Epstein, R. S. \& BARry, W. H. (1961) Use of potassium tartrate for equilibrium density gradient centrifugation of animal viruses. Nature, Lond. 189, 220.

Meselson, M., Stahl, F. W. \& Vinograd, J. (1957) Equilibrium sedimentation of macromolecules in density gradients. Proc. natn. Acad. Sci. U.S.A. 43, 581.

Redenz, E. (1933) Uber den Spaltungsstoffwechsel der Saugetierspermatozoen im Zusammenhang mit der Beweglichkeit. Biochem Z. 257, 234.

SAACKE, R. G. (1962) An electron microscope study of normal bovine spermatozoa and factors affecting structural integrity. Ph.D. thesis, Pennsylvania State University.

Salisbury, G. W. \& VanDemark, N. L. (1961) Physiology of reproduction and artificial insemination of cattle. Freeman, San Francisco.

White, I. G. \& MAcLeod, J. (1963) Composition and physiology of semen. Mechanisms Concerned with Conception, chap. III. Ed. C. G. Hartman. Macmillan, New York. 